\title{
Structural effects of polyethers and ionic liquids in their binary mixtures on lower critical solution temperature liquid-liquid phase separation
}

\author{
Koichi Kodama, Ryohei Tsuda, Kazuyuki Niitsuma, Takashi Tamura, Takeshi Ueki, Hisashi Kokubo \\ and Masayoshi Watanabe
}

The solubility and phase behavior of five polyethers (poly(ethylene oxide), poly(glycidyl methyl ether), poly(ethyl glycidyl ether), poly(ethoxyethyl glycidyl ether) and poly(propylene oxide)) in 14 different room-temperature ionic liquids (ILs) were studied by changing the structures of polyethers and the cations and anions in the ILs. Certain combinations of a polyether and an IL binary mixture exhibited lower critical solution temperature (LCST) phase behavior. For ILs containing the same anions, the polyethers were highly soluble in imidazolium- or pyridinium-based ILs, whereas they were insoluble in ammonium- or phosphonium-based ILs. An increase in length of the alkyl chain in the imidazolium cation and an increase in polarity of the polyethers resulted in a higher LCST phase separation temperature, whereas substitution of the hydrogen atoms on the imidazolium ring by methyl groups resulted in a lower LCST phase separation temperature. The hydrogen bonding interaction between the oxygen atoms in the polyethers and the aromatic hydrogen atoms on the cations in the ILs had an important role in the LCST phase behavior of the mixtures. Miscibility of the mixtures was also affected by the Lewis basicity of the anions in the ILs.

Polymer Journal (2011) 43, 242-248; doi:10.1038/pj.2010.140; published online 19 January 2011

Keywords: hydrogen bonding interaction; ionic liquid; lower critical solution temperature; phase separation; polyether

\section{INTRODUCTION}

Ionic liquids (ILs) have attracted increasing attention owing to their unique and advantageous properties such as negligible volatility, nonflammability, high ionic conductivity and high thermal stability. ${ }^{1-4}$ ILs consist entirely of ions and are in the liquid state at ambient temperatures, which make them unique solvents. Another advantage of ILs is that it is easy to tune their physicochemical properties by changing the combination of cations and anions. In a previous study, we systematically investigated the effect of cationic and anionic structures on the basic physicochemical properties of ILs, such as viscosity, ionic conductivity and ionic diffusivity. ${ }^{5-7}$ ILs have been successfully used in various fields; ${ }^{1-4}$ for example, they have been applied to separation technology and catalysis, and they have been used as reaction media for organic syntheses and as electrolytes for electrochemical devices. Thus, ILs, a new class of solvents, are gradually replacing conventional organic solvents. Therefore, it is important to gain a detailed understanding of the fundamental properties of ILs. In particular, the solubility of various compounds in ILs is a rapidly progressing area of research.

ILs have been used as solvents for organic compounds and for biopolymers such as enzymes and cellulose. ${ }^{8-11}$ Furthermore, many liquid-liquid phase equilibrium systems such as IL/water and IL/ organic solvent systems have been presented; this indicates the possibility of utilizing ILs as reaction or extraction solvents. ${ }^{12-15}$ For example, it has been shown that 1-alkyl-3-methylimidazolium bis(trifluoromethane sulfonyl)amide $\left(\left[\mathrm{C}_{\mathrm{n}} \mathrm{mim}\right]\left[\mathrm{NTf}_{2}\right]\right)$, a typical hydrophobic IL, can be used for the extraction of aromatic compounds from aliphatic hydrocarbons. ${ }^{16-18}$ Brennecke and co-workers have examined the phase behavior of IL/alcohol mixtures thoroughly and revealed their upper critical solution temperature behavior. ${ }^{19-21}$ Other binary systems such as IL/haloalkane, ${ }^{22,23} \mathrm{IL} / \mathrm{CO}_{2},{ }^{24,25} \mathrm{IL} /$ $\mathrm{IL}^{26,27}$ and IL/synthetic polymer ${ }^{28-36}$ systems have also exhibited unique phase behavior. This unique phase behavior has not only given us a better understanding of ILs but has also highlighted their potential for use in several applications, for example, in separation and purification processes and stimuli-responsive polymers.

In our previous study, we reported the lower critical solution temperature (LCST) phase separation behavior of polyethers in water. $^{37,38}$ Poly (ethyl glycidyl ether) (PEGE) is one of the polyethers that exhibit reversible LCST phase separation in an aqueous solution. We also developed diblock copolymers containing a thermoresponsive PEGE segment and a hydrophilic poly(ethylene oxide) (PEO) 
segment; we examined the aggregation behavior of these copolymers in aqueous media in response to temperature through electrochemical, dynamic light scattering and pulsed-gradient spin-echo nuclear magnetic resonance (NMR) measurements. ${ }^{39,40}$ We found that the block copolymers formed micelles by the aggregation of the PEGE segments at high temperatures, whereas they dissolved as unimers at low temperatures. ${ }^{39,40}$

Recently, it was found that PEGE exhibits LCST phase behavior not only in water but also in $\left[\mathrm{C}_{2} \mathrm{mim}\right]\left[\mathrm{NTf}_{2}\right]$. Previous studies have indicated that the hydrogen bonds between the ether oxygen atoms of PEGE and the aromatic hydrogen atoms of imidazolium cations have an important role in inducing the liquid-liquid LCST phase behavior. ${ }^{41} \mathrm{~A}$ mixture of $\mathrm{PEO} /$ imidazolium-based ILs containing $\left[\mathrm{BF}_{4}\right]$ anions has been reported to show similar phase behavior. ${ }^{42}$ However, the structural effects of polyethers and ILs on LCST liquidliquid phase separation behavior still remain unclear. In the present study, to understand this unique phase behavior in ILs, we investigate the LCST phase behavior of several polyethers, including PEGE, in ILs and the structural effects of ILs on phase separation. In this study, we discuss the thermodynamic aspects of phase separation on the basis of van't Hoff plots of the partition coefficients of PEGE from a PEGErich phase to a $\left[\mathrm{C}_{2} \mathrm{mim}\right]\left[\mathrm{NTf}_{2}\right]$-rich phase; the coefficients were calculated from the full phase diagram of PEGE/ $\left[\mathrm{C}_{2} \mathrm{mim}\right]\left[\mathrm{NTf}_{2}\right]$ binary mixtures. ${ }^{41}$

\section{EXPERIMENTAL PROCEDURE}

\section{Preparation and characterization of polyethers}

The chemical structures of the polyethers used in this study are summarized in Scheme 1. PEO and poly(propylene oxide) (PPO) were purchased from SigmaAldrich Japan K. K. (Tokyo, Japan). Except for PEO and PPO, all polyethers were synthesized by ring-opening anionic polymerization of the corresponding epoxide monomer in the presence of an appropriate base, which behaved as an initiator. ${ }^{39,40}$
A typical procedure for the polyether preparation is shown by using an example of PEGE, as follows. Solid naphthalene was charged in a dried roundbottom flask under a $\mathrm{N}_{2}$ atmosphere followed by the addition of dry tetrahydrofuran or dry dimethoxyethane. To the clear solution, solid potassium was added portionwise, and the solution was stirred at room temperature for $6 \mathrm{~h}$. The resultant potassium naphthalenide solution was stored in the refrigerator after $\mathrm{N}_{2}$ gas was purged. The concentration of this stock solution was determined by titration using aqueous hydrochloric acid.

Butoxyethanol was charged in a round-bottom flask and dissolved in dry tetrahydrofuran or dry dimethoxyethane $(20-50 \mathrm{mM})$, followed by the addition of potassium naphthalenide solution (equimolar to butoxyethanol) under a $\mathrm{N}_{2}$ atmosphere. The solution was stirred at room temperature for $15 \mathrm{~min}$, ethyl glycidyl ether was added, and the solution was stirred at $60^{\circ} \mathrm{C}$ for $48 \mathrm{~h}$. After the solution was cooled to room temperature, $2 \mathrm{M}$ hydrochloric acid was added to quench the reaction, and the resultant solid was filtered off. The filtrate was evaporated and dried under vacuum at $60^{\circ} \mathrm{C}$. The remaining liquid product was dissolved in methanol and vigorously stirred overnight in the presence of Amberlite MB-3 (Organo Co. Ltd., Tokyo, Japan). After filtration, the filtrate was evaporated and dried under vacuum at $60^{\circ} \mathrm{C}$. To remove the remaining naphthalene, hexane was added to the viscous liquid, and the solution was kept in the freezer for $6 \mathrm{~h}$ to yield biphasic solution. The upper phase was removed, and fresh hexane was added to the solution. This operation was repeated thrice, and the resultant solution was evaporated and dried under vacuum at $80^{\circ} \mathrm{C}$ for 3 days to afford PEGE as a viscous liquid (yield: 50-90\%).

The preparation of poly(methyl glycidyl ether) and poly(ethoxyethyl glycidyl ether) (PEEGE) followed a similar way to PEGE. All the polyethers were dried under vacuum at $60^{\circ} \mathrm{C}$ and characterized by ${ }^{1} \mathrm{H}$ NMR and gel permeation chromatography measurements (Table 1). Gel permeation chromatography measurement (Tosoh columns; Tosoh, Tokyo, Japan; eluent: tetrahydrofuran) was recorded using PEO or polystyrene standard samples as reference.

\section{Preparation and characterization of ILs}

The structures and abbreviation of cations and anions for the ILs used in this study are also shown in Scheme 1. The ILs were synthesized by using the methods described in literature. ${ }^{5-7}$ The details of preparation and characterization

\section{Polyethers}<smiles>CCn1cc[n+](C)c1</smiles>

$\left[C_{n} \operatorname{mim}\right](n=1-4,8)$<smiles>CCCn1cc[n+](C)c1C</smiles>

[C $C_{n}$ dmim] $(n=3-6)$<smiles></smiles>

$\left[\mathrm{C}_{4} \mathrm{~m}_{4} \mathrm{im}\right]$<smiles>CCOCC(CC)OCC</smiles><smiles>CCC(COC)OC</smiles>

PGME<smiles>CCOCCOC(CC)COCC</smiles>

PEEGE<smiles>CC(=O)[O-]</smiles>

$$
\text { [C } 4 \text { py] }
$$<smiles>CCCCCN1CCCC1</smiles>

[Py $\left.{ }_{14}\right]$<smiles>C[N+](C)(C)[Na]</smiles><smiles>CCCCCCP(C)(CC)(CC)CCC</smiles>

[ $\mathrm{P}_{\text {2225 }}$ ]<smiles>F[B-](F)(F)F</smiles>

$\left[\mathrm{BF}_{4}\right]$<smiles>CS(=O)(=O)[O-]</smiles><smiles>O=S(=O)([O-])C(F)(F)F</smiles>

[OTf]

$\left[\mathrm{PF}_{6}\right]$<smiles>CCCCC(C)OC(C)CCOCCCO</smiles><smiles>O=S(=O)(NS(=O)(=O)C(F)(F)F)C(F)(F)F</smiles><smiles>FP(F)(F)(F)(F)(F)F</smiles><smiles>O=S(=O)(NS(=O)(=O)C(F)(F)C(F)(F)C(F)(F)F)C(F)(F)C(F)(F)F</smiles>

[BETI]

Cations

Anions

Scheme 1 Structures of polyethers as well as cations and anions in the ionic liquids used in this study. PEEGE, poly(ethoxyethyl glycidyl ether); PEGE, poly(ethyl glycidyl ether); PEO, poly(ethylene oxide); PGME, poly(glycidyl methyl ether). 
of ILs are shown in the Supplementary Information. $\left[\mathrm{P}_{5222}\right]\left[\mathrm{NTf}_{2}\right]$ was obtained from Nippon Chemical Industrial Co. Ltd. (Tokyo, Japan). All the ILs were dried under vacuum at $60^{\circ} \mathrm{C}$, characterized by ${ }^{1} \mathrm{H} N \mathrm{NMR}$, and stored in a glovebox $\left(\left[\mathrm{O}_{2}\right],\left[\mathrm{H}_{2} \mathrm{O}\right]<1\right.$ p.p.m. $)$.

The water content in the ILs was measured using the Karl-Fischer titration method and was found to be <110 p.p.m.

Thermogravimetric measurements of the polymer, IL, and their mixtures were recorded in air. The samples were heated from 30 to $500{ }^{\circ} \mathrm{C}$ at a rate of $10^{\circ} \mathrm{C} \mathrm{min}{ }^{-1}$.

\section{Measurement of phase separation temperature of polyether/IL mixtures}

The sample solutions used in the determination of the phase separation temperature were prepared by directly mixing polyethers and ILs in a glovebox under an Ar atmosphere in order to eliminate the influence of moisture. A sample solution was placed in a vial tube, which was sealed under an Ar atmosphere, and then gradually heated in a water or oil bath at a rate of $0.2^{\circ} \mathrm{C} \mathrm{min}^{-1}$ or $0.5^{\circ} \mathrm{C} \mathrm{min}^{-1}$ from room temperature to $200^{\circ} \mathrm{C}$. When the solution became turbid, as observed by the naked eye, the temperature was recorded as the phase separation temperature. This is a common way of measuring the temperature at which liquid-liquid phase separation occurs. ${ }^{19-21}$ The phase separation temperature is also called the cloud point. We repeated turbidity measurements at least three times, and confirmed that the phase transition temperature for each measurement is within $0.2^{\circ} \mathrm{C}$.

\section{RESULTS AND DISCUSSION}

To explore the structural effect of polyethers and ILs on the phase behavior of their mixtures, we used five polyethers: PEGE, poly (glycidyl methyl ether) (PGME), PEEGE PEO and PPO (Scheme 1). The $M_{\mathrm{n}}, M_{\mathrm{w}}$ and $M_{\mathrm{w}} / M_{\mathrm{n}}$ values of the polymers used in this study are

Table $1 M_{\mathrm{n}}, M_{\mathrm{w}}$, and $M_{\mathrm{w}} / M_{\mathrm{n}}$ of polyethers used in this study

\begin{tabular}{lccc}
\hline Polyether & $M_{n} /$ Da $\left({ }^{1} \mathrm{H} N M R\right)$ & $M_{w} / D a(G P C)$ & $M_{w} / M_{n}$ \\
\hline PEGE $_{37}$ & $3.8 \times 10^{3}$ & - & 1.15 \\
PEGE $_{79}$ & $8.1 \times 10^{3}$ & - & 1.19 \\
PEGE $_{97}$ & $1.0 \times 10^{4}$ & - & 1.26 \\
PEGE $_{216}$ & $2.2 \times 10^{4}$ & - & 1.75 \\
PEO $^{\text {a }}$ & - & $3.8 \times 10^{3}$ & 1.06 \\
PPO $^{\text {a }}$ & - & $3.9 \times 10^{3}$ & 1.15 \\
PGME $_{\text {PEEGE }}^{\text {b }}$ & $3.0 \times 10^{3}$ & - & 1.19 \\
\hline
\end{tabular}

Abbreviations: GPC, gel permeation chromatography; NMR, nuclear magnetic resonance; PEEGE, poly(ethoxyethyl glycidyl ether); PEGE, poly(ethyl glycidyl ether); PEO, poly(ethylene oxide); PGME, poly(glycidyl methyl ether).

Oxide); PGME, poly(glycidyl methyl ether).
aDetermined by GPC calibrated by PEO standards.

betermined by GPC calibrated by polystyrene standards. summarized in Table 1 . In the case of PEGE, $\mathrm{PEGE}_{79}$ was mainly used, unless stated otherwise.

Influence of cation structures on phase separation temperatures The effect of cation structures of ILs on the phase behavior was examined by using 14 different ILs containing imidazolium, pyridinium, ammonium and phosphonium cations along with the $\left[\mathrm{NTf}_{2}\right]$ anion; the ILs were prepared in this study. The miscibility and phase separation behavior of $10 \mathrm{wt} \% \mathrm{PEGE} / \mathrm{IL}$ solutions were investigated and are summarized in Figure 1. PEGE exhibits LCST phase separation in most of the imidazolium ILs. Furthermore, it is miscible in the pyridinium IL, whereas it is immiscible in the ammonium and phosphonium ILs at temperatures ranging from room temperature to $200^{\circ} \mathrm{C}$. This result clearly shows that PEGE is more soluble in ILs containing aromatic cations, and it supports the fact that the hydrogen bonds between the oxygen atoms of PEGE and the acidic hydrogen atoms in the aromatic cations are essential for increasing its miscibility. It has been indicated that the intermolecular hydrogen bonds between PEGE and imidazolium cations break at high temperatures, resulting in phase separation of PEGE from imidazolium ILs. On the other hand, the ILs containing ammonium or phosphonium cations have low miscibility with PEGE because of the lack of acidic protons in the cations.

The phase separation temperatures of PEGE/imidazolium ILs, as a function of PEGE concentration, were measured by focusing on the effect of length of the alkyl chain in the imidazolium cations (Figure 2). The phase separation temperature increases with an increase in length of the alkyl chain in the imidazolium cations (methyl<ethyl $<$ propyl $<$ butyl). Consequently, PEGE is completely miscible in $\left[\mathrm{C}_{8} \mathrm{mim}\right]\left[\mathrm{NTf}_{2}\right]$ in the measurement temperature and concentration ranges. An increase in the miscibility of imidazolium ILs with longer alkyl chains was also observed in other binary mixture systems, alcohol/IL systems and polymethacrylate/IL systems. ${ }^{19-21,28-36}$ LCST phase separation of binary mixtures is governed by the magnitude of negative enthalpy and negative entropy changes of mixing (vide infra). A large decrease in the latter results in lower phase separation temperatures. It is well known that imidazolium ILs tend to form phase-separated self-assembled structures as the alkyl chain length increases, ${ }^{43-45}$ which indicates that the entropy of the imidazolium ILs itself decreases with an increase in the alkyl chain length. It is plausible to consider that the increase in alkyl chain length gives rise to a small decrease in the entropy of mixing, as the entropy of the IL itself decreases because of the structure formation, and thus, a large decrease in mixing entropy hardly occurs.

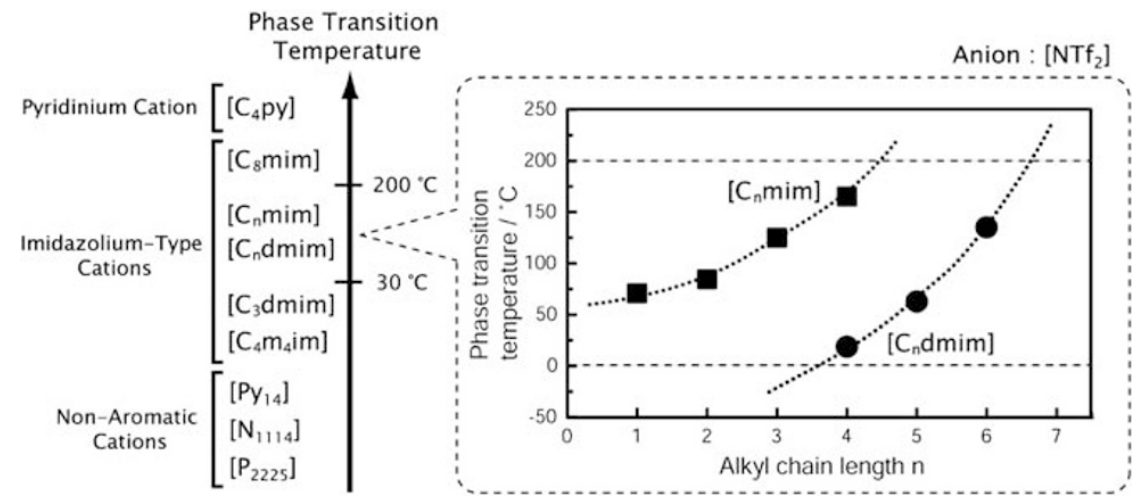

Figure 1 Solubility behavior and lower critical solution temperature phase separation temperatures of 10 wt\% poly(ethyl glycidyl ether) in ionic liquids containing $\left[\mathrm{NTf}_{2}\right]$ anions at temperatures ranging from room temperature to $200^{\circ} \mathrm{C}$. 

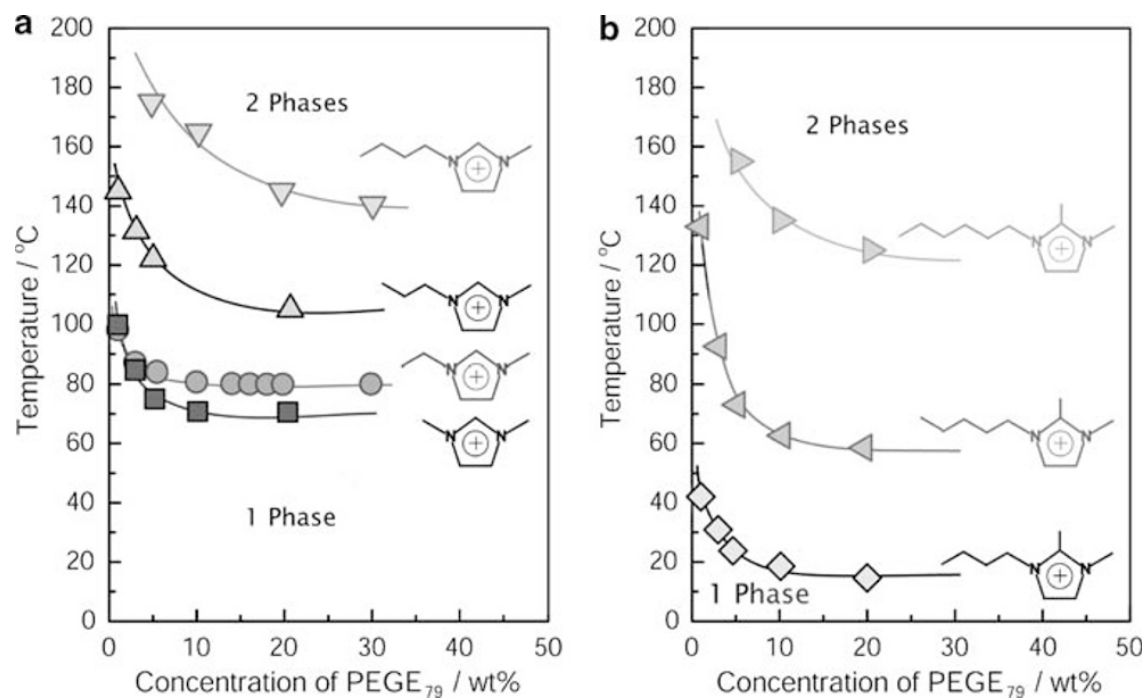

Figure 2 Phase separation temperatures for binary mixtures containing poly(ethyl glycidyl ether) $(\mathrm{PEGE}) /\left[\mathrm{C}_{n} \mathrm{mim}\right]\left[\mathrm{NTf} \mathrm{f}_{2}\right]$ or $\mathrm{PEGE} /\left[\mathrm{C}_{n} \mathrm{dmim}\right]\left[\mathrm{NTf} \mathrm{f}_{2}\right]$ as a function of PEGE concentration.

The effect of substitution of the imidazolium C-2 proton by a methyl group has also been investigated (Figures 1 and 2). It was found that the phase separation temperatures reduce considerably owing to methylation of the corresponding imidazolium cations. The phase separation temperature of PEGE/ $\left[\mathrm{C}_{4} \mathrm{dmim}\right]\left[\mathrm{NTf}_{2}\right]$ is $\sim 120^{\circ} \mathrm{C}$ lower than that of $\mathrm{PEGE} /\left[\mathrm{C}_{4} \mathrm{mim}\right]\left[\mathrm{NTf}_{2}\right]$, although the only structural difference is either the presence or the absence of a methyl substituent at the $\mathrm{C}-2$ position. As the imidazolium C-2 proton is the most acidic proton, it was strongly suggested that the hydrogen bonds between the ether oxygen atoms of PEGE and the hydrogen atoms on the imidazolium cations have a critical role in the LCST phase behavior, as indicated in our previous report. ${ }^{41}$ This trend is in clear contrast to that in the case of the previously reported poly(benzyl methacrylate)/ IL systems, in which the phase separation temperatures of $\left[\mathrm{C}_{4} \mathrm{mim}\right]\left[\mathrm{NTf}_{2}\right]$ and $\left[\mathrm{C}_{4} \mathrm{dmim}\right]\left[\mathrm{NTf}_{2}\right]$ are similar. ${ }^{32}$ The hydrogenbond accepting ability (or electron-donating ability) of ester groups in polymethacrylates is lower than that of the ether groups, as the donor number of ether groups is $\sim 20$ and that of ester groups is $\sim 15{ }^{46}$ Such differences in chemical nature between polyethers and polymethacrylates lead to different solubilities for ILs with different hydrogen bond donating abilities. The phase separation temperatures of PEGE/[C $\left.\mathrm{C}_{\mathrm{n}} \mathrm{dmim}\right]\left[\mathrm{NTf}_{2}\right](n=4-6)$ also increase from 20 to $140^{\circ} \mathrm{C}$ with an increase in the alkyl chain length (Figure 1). It is noteworthy that additional methylation of the remaining two hydrogen atoms of the $\left[\mathrm{C}_{4} \mathrm{dmim}\right]$ cation further decreases the miscibility of PEGE. This is because the $\left[\mathrm{C}_{4} \mathrm{~m}_{4} \mathrm{im}\right]$ cation has no hydrogen-bonding ability to promote dissolution of PEGE. It is possible to control phase separation temperatures over a wide range, from room temperature to $200^{\circ} \mathrm{C}$, by appropriately selecting the cation structures.

\section{Influence of anion structures on phase separation temperatures}

The effect of anion structures in the imidazolium ILs on the miscibility of PEGE has also been investigated. The miscibilities of a $10 \mathrm{wt} \%$ solution of PEGE/imidazolium IL are summarized in Table 2. PEGE shows LCST phase separation in ILs containing imide anions, such as $\left[\mathrm{C}_{2} \mathrm{mim}\right]\left[\mathrm{NTf}_{2}\right]$ and $\left[\mathrm{C}_{4} \mathrm{mim}\right]\left[\mathrm{NTf}_{2}\right]$, whereas it is immiscible in $\left[\mathrm{C}_{4} \mathrm{mim}\right][\mathrm{OTf}]$ and $\left[\mathrm{C}_{4} \mathrm{mim}\right]\left[\mathrm{PF}_{6}\right]$. When a longer alkyl chain is introduced in the imidazolium cation, $\mathrm{PEGE} /\left[\mathrm{C}_{8} \mathrm{mim}\right]\left[\mathrm{PF}_{6}\right]$ shows LCST phase separation; therefore, the LCST behavior is not specific
Table 2 Solubility behavior and LCST phase separation temperatures of 10 wt $\%$ PEGE in ILs containing $\left[\mathrm{C}_{2} \mathrm{mim}\right],\left[\mathrm{C}_{4} \mathrm{mim}\right]$ or $\left[\mathrm{C}_{8} \mathrm{mim}\right]$ cations at temperatures ranging from room temperature to $200{ }^{\circ} \mathrm{C}$

\begin{tabular}{llllrlll}
\hline Entry & Cation & Anion & Solubility & Entry & Cation & Anion & Solubility \\
\hline 1 & {$\left[\mathrm{C}_{2} \mathrm{mim}\right]$} & {$\left[\mathrm{NTf}_{2}\right]$} & $84.4^{\circ} \mathrm{C}$ & 6 & {$\left[\mathrm{C}_{4} \mathrm{mim}\right]$} & {$\left[\mathrm{NTf}_{2}\right]$} & $167.4{ }^{\circ} \mathrm{C}$ \\
2 & {$\left[\mathrm{C}_{2} \mathrm{mim}\right]$} & {$[\mathrm{OTf}]$} & Immiscible & 7 & {$\left[\mathrm{C}_{4} \mathrm{mim}\right]$} & {$[\mathrm{OTf}]$} & Immiscible \\
3 & {$\left[\mathrm{C}_{2} \mathrm{mim}\right]$} & {$[\mathrm{OMs}]$} & Immiscible & 8 & {$\left[\mathrm{C}_{4} \mathrm{mim}\right]$} & {$\left[\mathrm{BF}_{4}\right]$} & Immiscible \\
4 & {$\left[\mathrm{C}_{2} \mathrm{mim}\right]$} & {$[\mathrm{OAc}]$} & Immiscible & 9 & {$\left[\mathrm{C}_{4} \mathrm{mim}\right]$} & {$\left[\mathrm{PF}_{6}\right]$} & Immiscible \\
5 & {$\left[\mathrm{C}_{4} \mathrm{mim}\right]$} & {$[\mathrm{BETI}]$} & Miscible & 10 & {$\left[\mathrm{C}_{8} \mathrm{mim}\right]$} & {$\left[\mathrm{PF}_{6}\right]$} & $67.0^{\circ} \mathrm{C}$ \\
\hline
\end{tabular}

Abbreviations: ILs, ionic liquids; LCST, lower critical solution temperature; PEGE, poly(ethyl glycidyl ether).

only to ILs containing imide anions. The solubility behavior is highly dependent on the anion structure, and the order of the miscibilities of PEGE is as follows:

$$
[\mathrm{BETI}]>\left[\mathrm{NTf}_{2}\right]>\left[\mathrm{PF}_{6}\right]>\left[\mathrm{BF}_{4}\right]>[\mathrm{OTf}],[\mathrm{OMs}],[\mathrm{OAc}]
$$

This order is not exactly but almost consistent with the order of the reported Lewis basicities of anions; ${ }^{47}$ PEGE is immiscible in ILs containing highly basic anions ([OTf], [OMs], [OAc]), whereas it is miscible in ILs containing less basic anions, such as [BETI] and $\left[\mathrm{NTf}_{2}\right]$. This tendency can be understood as a competition of the interaction counterparts of the imidazolium cation between PEGE and the anions, in which the cations are Lewis acids and PEGE and the anions are Lewis bases. Strongly basic anions tightly interact with imidazolium cations, particularly with the $\mathrm{C} 2$ proton of imidazolium cations. ${ }^{48}$ This interrupts the hydrogen-bonding interaction between PEGE and imidazolium cations, thereby lowering the miscibility. Such a tendency in miscibility is the same as that observed in alcohol/IL binary systems. ${ }^{19-21}$ The nature of ILs is largely influenced by the anion structures; therefore, the choice of an anion is another factor that determines the LCST phase behavior.

Influence of polymer structures on phase separation temperatures Various polyether surfactants are known to show LCST phase separation in aqueous media, and their structural effects and mechanisms have been extensively studied. ${ }^{49,50}$ Assuming that polyether structures also affect the LCST phase behavior in ILs, we have examined the 
Table 3 Solubility behavior and lower critical solution temperature phase separation temperatures of $10 \mathrm{wt} \%$ polyethers in imidazolium ionic liquids with $\left[\mathrm{NTf}_{2}\right]$ or $\left[\mathrm{PF}_{6}\right]$ anions at temperatures ranging from room temperature to $200{ }^{\circ} \mathrm{C}$

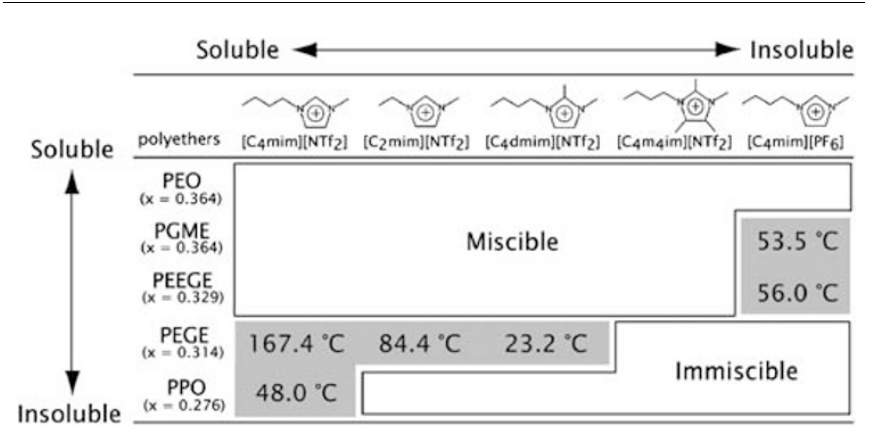

Abbreviations: PEEGE, poly(ethoxyethyl glycidyl ether); PEGE, poly(ethyl glycidyl ether); PEO, poly(ethylene oxide); PGME, poly(glycidyl methyl ether).

The oxygen weight fraction of the polyethers is denoted by ' $x$.

phase behavior of five different polyethers in five different ILs containing imidazolium cations. It has previously been reported, on the basis of a molecular dynamics simulation and a small-angle neutron scattering measurement, that PEO is compatible with certain ILs. ${ }^{51,52}$ Block copolymers containing PEO segments and IL-incompatible segments, which form micelles in ILs, have been studied and successfully utilized for micellar shuttles at the IL/water interfaces and in thermoreversible ion-gel formation. ${ }^{53-58}$ As shown in Table 3, polyethers other than PEO, such as PGME, PEEGE, PEGE and PPO, exhibit LCST phase separation in these ILs. This result is very important, because PPO and its block copolymers are commercially available and we can systematically examine these LCST behaviors. In addition, polyethers with higher oxygen weight fractions $(x)$ have better miscibility in these ILs. This is represented as follows:

$$
\begin{aligned}
\operatorname{PEO}= & \operatorname{PGME}(x=0.364)>\operatorname{PEEGE}(x=0.329) \\
& >\operatorname{PEGE}(x=0.314)>\operatorname{PPO}(x=0.276)
\end{aligned}
$$

This result suggests that the ether oxygen atom of polyethers significantly enhances the miscibility of polyethers with ILs through hydrogen bonding interactions; the phase separation temperature is determined from the balance between the solvatophobic alkyl chain and solvatophilic ether groups of the polyethers. It has recently been reported that negative mixing entropy, which results from solute/ solvent ordering, is caused by the formation of hydrogen bonds between the ether oxygen atoms of tetraethylene glycol or polyethylene glycol and the hydrogen atoms on the imidazolium $\mathrm{C} 2$ carbon of $\left[\mathrm{C}_{4} \mathrm{mim}\right]\left[\mathrm{PF}_{6}\right]$ or $\left[\mathrm{C}_{2} \mathrm{mim}\right][\mathrm{Cl}] .{ }^{59,60}$ In our case, the negative entropy and enthalpy of mixing can be attributed to the hydrogen bonds between the polyethers and imidazolium cations (vide infra).

\section{Thermal stability of PEGE/IL binary mixtures}

The hydrogen bonding interaction between PEGE and imidazolium cations in ILs may affect the thermal stability of the mixtures. Figure 3 shows the results of thermogravimetric measurements for PEGE, $\left[\mathrm{C}_{2} \mathrm{mim}\right]\left[\mathrm{NTf}_{2}\right]$, and the binary mixtures of these two compounds (30 and 50 wt $\%$ PEGE solution). Weight loss in neat PEGE and $\left[\mathrm{C}_{2} \mathrm{mim}\right]\left[\mathrm{NTf}_{2}\right]$ begins at $\sim 200$ and $400{ }^{\circ} \mathrm{C}$, respectively. The weight loss in binary mixtures occurs in two steps; PEGE and $\left[\mathrm{C}_{2} \mathrm{mim}\right]\left[\mathrm{NTf}_{2}\right]$ degrade independently, which is supported by the fact that the magnitude of weight loss is consistent with their mixing ratios. Interestingly, the weight loss in $\mathrm{PEGE} /\left[\mathrm{C}_{2} \mathrm{mim}\right]\left[\mathrm{NTf}_{2}\right]$ begins at $300^{\circ} \mathrm{C}$, which is

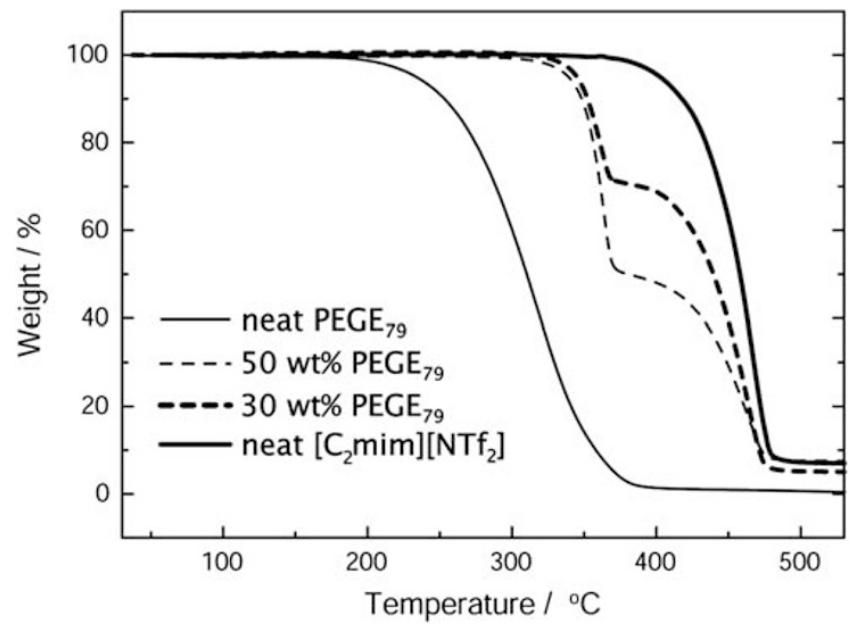

Figure 3 Results of thermogravimetric analysis of poly(ethyl glycidyl ether) $(\mathrm{PEGE}) /\left[\mathrm{C}_{2} \mathrm{mim}\right]\left[\mathrm{NTf}_{2}\right]$ binary mixtures with four different concentrations. Solid line: neat PEGE, broken line: 50 wt\% PEGE, bold broken line: 30 wt\% PEGE and bold solid line: neat $\left[\mathrm{C}_{2} \mathrm{mim}\right]\left[\mathrm{NTf}_{2}\right]$.

about $100{ }^{\circ} \mathrm{C}$ higher than that for neat PEGE. The phase diagrams for $\mathrm{PEGE} /\left[\mathrm{C}_{2} \mathrm{mim}\right]\left[\mathrm{NTf}_{2}\right]$ systems $^{41}$ indicate that PEGE (30 and $50 \mathrm{wt} \%$ )/ $\left[\mathrm{C}_{2} \mathrm{mim}\right]\left[\mathrm{NTf}_{2}\right]$ mixtures begin to phase separate into an IL-rich phase and a PEGE-rich phase at 80 and $85^{\circ} \mathrm{C}$, respectively. The PEGE-rich phases contain a considerable amount of $\left[\mathrm{C}_{2} \mathrm{mim}\right]\left[\mathrm{NTf}_{2}\right]$, which interacts with PEGE through hydrogen bonding, whereas $\left[\mathrm{C}_{2} \mathrm{mim}\right]\left[\mathrm{NTf}_{2}\right]-$ rich phases contain traces of PEGE. It is suggested that the hydrogen bonds between PEGE and the IL remain intact even at a high temperature, and that the degradation of PEGE is effectively inhibited by the interaction with $\left[\mathrm{C}_{2} \mathrm{mim}\right]\left[\mathrm{NTf}_{2}\right]$. It has also been confirmed that no degradation occurs in the range of temperatures at which phaseseparation-temperature measurements for the PEGE/IL binary mixtures (up to $200^{\circ} \mathrm{C}$ ) were recorded.

\section{Enthalpy and entropy changes for partition of PEGE from PEGE-rich phase to IL-rich phase}

Thermodynamic studies on LCST phase separation are of considerable interest, as the negative enthalpy of mixing $\left(\Delta H_{\text {mix }}\right)$ and negative entropy of mixing $\left(\Delta S_{\text {mix }}\right)$ are critical requirements for LCST phase separation. Previously, on the basis of highly sensitive differential scanning calorimetry measurements, we reported negative $\Delta H_{\text {mix }}$ and $\Delta S_{\text {mix }}$ for the LCST phase separation of poly(benzyl methacrylate)/ $\left[\mathrm{C}_{\mathrm{n}} \mathrm{mim}\right]\left[\mathrm{NTf}_{2}\right]$ binary mixtures. ${ }^{34}$ In the present study, we have estimated the enthalpy $(\Delta H)$ and entropy $(\Delta S)$ changes for the partition of PEGE from a PEGE-rich to a $\left[\mathrm{C}_{2} \mathrm{mim}\right]\left[\mathrm{NTf}_{2}\right]$-rich phase on the basis of van't Hoff plots of partition coefficients. ${ }^{26}$

When the PEGE/ $\left[\mathrm{C}_{2} \mathrm{mim}\right]\left[\mathrm{NTf}_{2}\right]$ binary system is phase separated, the components of the system are in the partition equilibrium state represented by equation (1), and the temperature dependence of the equilibrium partition coefficient $K$ is expressed by the van't Hoff equation, given as equation (2) $(\Delta H$ : enthalpy change due to the partition, $\Delta S$ : entropy change due to the partition, $R$ : gas constant, $T$ : absolute temperature).

$$
\begin{aligned}
& {[\mathrm{PEGE}]_{\mathrm{PEGE}-\text { rich phase }} \leftrightarrows[\mathrm{PEGE}]_{\mathrm{IL}-\text { rich phase }}} \\
& \ln K=-\frac{\Delta H}{R T}+\frac{\Delta S}{R}
\end{aligned}
$$

On the other hand, the equilibrium partition coefficient $K$ is directly calculated from the full phase diagrams of the PEGE/[C $\left.\mathrm{C}_{2} \mathrm{mim}\right]\left[\mathrm{NTf}_{2}\right]$ 


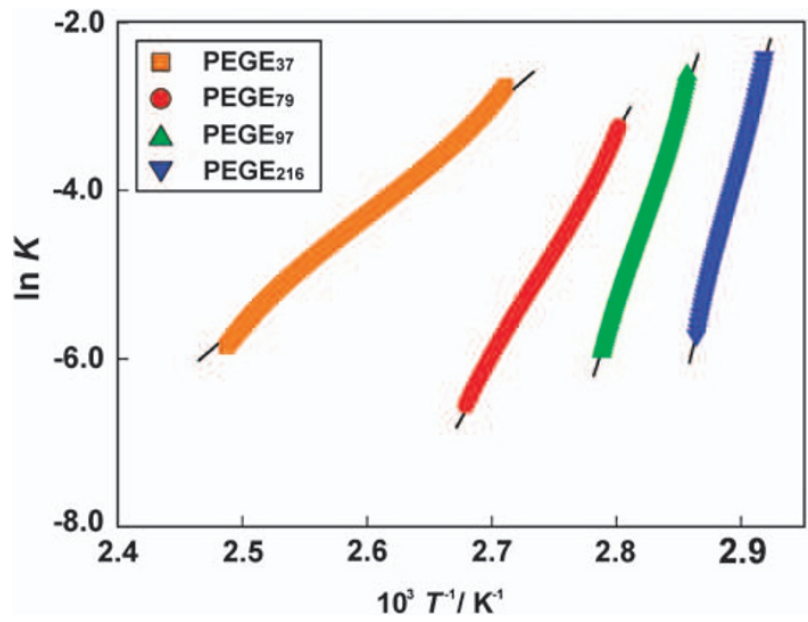

Figure 4 van't Hoff plots of partition coefficients of poly(ethyl glycidyl ethers) (PEGEs) with four different molecular weights from PEGE-rich phase to $\left[\mathrm{C}_{2} \mathrm{mim}\right]\left[\mathrm{NTf}_{2}\right]$-rich phase.

binary mixtures, which have been reported in the previous paper, ${ }^{41}$ by using equation (3) ( $w_{\mathrm{IL}}$ : weight fraction of PEGE in an IL-rich phase, $w_{\text {PEGE }}$ : weight fraction of PEGE in a PEGE-rich phase, $M_{\mathrm{n}}$ : number average molecular weight of PEGE).

$$
K=\frac{\frac{w_{\mathrm{IL}} / M_{\mathrm{n}}}{\left(w_{\mathrm{IL}} / M_{\mathrm{n}}\right)+\left(\left(1-w_{\mathrm{IL}}\right) / 391.3\right)}}{\frac{w_{\mathrm{PEGE}} / M_{\mathrm{n}}}{\left(w_{\mathrm{PEGE}} / M_{\mathrm{n}}\right)+\left(\left(1-w_{\mathrm{PEGE}}\right) / 391.3\right)}}
$$

The plots of $\ln K$ versus $T^{-1}$ for four different mixtures of PEGEs/ $\left[\mathrm{C}_{2} \mathrm{mim}\right]\left[\mathrm{NTf}_{2}\right]$ gave straight lines with negative intercepts and positive slopes, as shown in Figure 4 , and $\Delta H$ and $\Delta S$ were calculated from the slope and intercept of these lines, respectively.

The estimated values of $\Delta H$ and $\Delta S$ are summarized in Table 4. It should be noted that the partition coefficients were determined from equation (3), which means that the coefficients were calculated on the basis of $M_{\mathrm{n}}$ of PEGE, and the slopes and intercepts became more positive and negative, respectively, with increasing the $M_{\mathrm{n}}$. On the other hand, the thermodynamic parameters in Table 4 were calculated on the basis of unit mass ( $\mathrm{g}$ ) and the unit mole. It was found that all the $\Delta H$ and $\Delta S$ values were negative, irrespective of the molecular weight of PEGEs, which indicate that the partition (dissolution) of PEGE into $\left[\mathrm{C}_{2} \mathrm{mim}\right]\left[\mathrm{NTf}_{2}\right]$-rich phases is favorable in terms of enthalpy change but unfavorable in terms of entropy change. The dissolution of PEGE in $\left[\mathrm{C}_{2} \mathrm{mim}\right]\left[\mathrm{NTf}_{2}\right]$ resulted in the formation of more ordered structures because of the hydrogen bonding between the ether oxygen atoms and imidazolium protons. The exothermic dissolution, accompanied by a more ordered structure, thermodynamically supports the observed LCST phase behavior.

\section{Conclusion}

In this study, we explored the effect of systematic modification of the structures of polyethers and ILs on their liquid-liquid LCST phase separation behavior. We found that the miscibility of polymers/ILs was enhanced by the following factors: (1) the polarity of the polyethers, (2) the presence of acidic hydrogen atoms on the cationic structures, (3) the length of the $\mathrm{N}$-substituted alkyl chain of the imidazolium cations and (4) the Lewis basicity of the anions. The main interactions between the polyethers and ILs occur via hydrogen bonds, as indicated by the high miscibility in ILs containing aromatic cations and the drastic decrease in miscibility in ILs containing methylated
Table 4 Enthalpy and entropy changes for partition of poly(ethyl glycidyl ethers) (PEGEs) from PEGE-rich phase to $\left[\mathrm{C}_{2}\right.$ mim $]\left[\mathrm{NTf}_{2}\right]$-rich phase, estimated from van't Hoff plots

\begin{tabular}{lrcr}
\hline Polymer & $\mathrm{n}$ & $\begin{array}{c}\Delta \mathrm{H} / \mathrm{Jg}^{-1} \text { of polymer } \\
(\mathrm{kJ} \text { unit mol }\end{array}$ & $\begin{array}{c}\Delta S / \mathrm{JK}^{-1} \mathrm{~g}^{-1} \text { of polymer } \\
\left(\mathrm{JK}^{-1} \text { unit mol }^{-1}\right)\end{array}$ \\
\hline PEGE $_{37}$ & 37 & $-29(-2.92)$ & $-0.084(-8.55)$ \\
PEGE $_{79}$ & 79 & $-26(-2.69)$ & $-0.077(-7.90)$ \\
PEGE $_{97}$ & 97 & $-38(-3.89)$ & $-0.11(-11.3)$ \\
PEGE $_{216}$ & 216 & $-22(-2.22)$ & $-0.064(-6.56)$ \\
\hline
\end{tabular}

imidazolium cations. As indicated by thermogravimetric measurements, the dominant interaction was further supported by the increased thermal stability of PEGE, which resulted from mixing of PEGE with $\left[\mathrm{C}_{2} \mathrm{mim}\right]\left[\mathrm{NTf}_{2}\right]$. The van't Hoff plots of the partition coefficients of partition of PEGE from a PEGE-rich phase to a $\left[\mathrm{C}_{2} \mathrm{mim}\right]\left[\mathrm{NTf}_{2}\right]$-rich phase indicated negative enthalpy and entropy changes for the dissolution of PEGE in $\left[\mathrm{C}_{2} \mathrm{mim}\right]\left[\mathrm{NTf}_{2}\right]$, which are essential for systems to exhibit LCST phase behavior.

\section{ACKNOWLEDGEMENTS}

This work was supported in part by a Grant-in-aid for Scientific Research (No. 452/17073009 and No. B/20350104) from MEXT, Japan.

1 Ionic Liquids in Synthesis (eds. Wasserscheid, P., Welton, T.) (Wiley-VCH Verlag, GmbH \& Co, KgaA, Weinheim, 2003).

2 Welton, T. Room-temperature ionic liquids. Solvents for synthesis and catalysis. Chem. Rev. 99, 2071 (1999).

3 Smiglak, M., Metlen, A. \& Rogers, R. D. The second evolution of ionic liquids: from solvents and separations to advanced materials-energetic examples from the ionic liquid cookbook. Acc. Chem. Res. 40, 1182 (2007).

4 Plechkova, N. V. \& Seddon, K. R. Applications of ionic liquids in the chemical industry. Chem. Soc. Rev. 37, 123 (2008).

5 Tokuda, H., Hayamizu, K., Ishii, K., Susan, M.A.B.H. \& Watanabe, M. Physicochemical properties and structures of room temperature ionic liquids. 1. Variation of anionic species. J. Phys. Chem. B 108, 16593 (2004).

6 Tokuda, H., Hayamizu, K., Ishii, K., Susan, M.A.B.H. \& Watanabe, M. Physicochemical properties and structures of room temperature ionic liquids. 2. Variation of alkyl chain length in imidazolium cation. J. Phys. Chem. B 109, 6103 (2005).

7 Tokuda, H., Ishii, K., Susan, M.A.B.H., Tsuzuki, S., Hayamizu, K. \& Watanabe, M. Physicochemical properties and structures of room-temperature ionic liquids. 3. Variation of cationic structures. J. Phys. Chem. B 110, 2833 (2006).

8 Madeira Lau, R., Van Rantwijk, F., Seddon, K. R. \& Sheldon, R. A. Lipase-catalyzed reactions in ionic liquids. Org. Lett. 2, 4189 (2000).

9 Swatloski, R. P., Spear, S. K., Holbrey, J. D. \& Rogers, R. D. Dissolution of cellulose with ionic liquids. J. Am. Chem. Soc. 124, 4974 (2002).

10 Fort, D. A., Remsing, R. C., Swatloski, R. P., Moyna, P., Moyna, G. \& Rogers, R. D. Can ionic liquids dissolve wood? Processing and analysis of lignocellulosic materials with 1-ethyl-3-methylimidazolium chloride. Green Chem. 9, 63 (2007).

11 Ohno, H. \& Fukaya, Y. Task specific ionic liquids for cellulose technology. Chem. Lett. 38, 2 (2009).

12 Huddleston, J. G. \& Rogers, R. D. Room temperature ionic liquids as novel media for 'clean' liquid-liquid extraction. Chem. Commun. 1998, 1765 (1998).

13 Rebelo, L. P. N., Najdanovic-Visak, V., Visak, Z. P., Nunes da Ponte, M., Szydlowski, J., Cerdeirina, C. A., Troncoso, J., Romani, L., Esperanca, J.M.S.S., Guedes, H. J. R. \& Sousa, H. C. A detailed thermodynamic analysis of $\left[\mathrm{C}_{4} \mathrm{mim}\right]\left[\mathrm{BF}_{4}\right]+$ water as a case study to model ionic liquid aqueous solution. Green Chem. 6, 369 (2004).

14 Fukumoto, K. \& Ohno, H. LCST-type phase changes of a mixture of water and ionic liquids derived from amino acids. Angew. Chem. Int. Ed. 46, 1852 (2007).

15 Mellein, B. R., Aki, S.N.V.K., Ladewski, R. L. \& Brennecke, J. F. Solvatochromic studies of ionic liquid/organic mixtures. J. Phys. Chem. B 111, 131 (2007).

16 Su, B. M., Zhang, S. \& Zhang, Z. C. Structural elucidation of thiophene interaction with ionic liquids by mulinuclear NMR spectroscopy. J. Phys. Chem. B 108, 19510 (2004).

17 Lachwa, J., Szydlowski, J., Makowska, A., Seddon, K. R., Esperanca, J.M.S.S., Guedes, H. J. R. \& Rebelo, L. P. N. Changing from an unusual high-temperature demixing to a UCST-type in mixtures of 1-alkyl-3-methylimidazolium bis\{(trifluoromethyl)sulfonyl\}amide and arenes. Green Chem. 8, 262 (2006).

18 Arce, A., Earle, M. J., Rodrỳguez, H. \& Seddon, K. R. Separation of benzene and hexane by solvent extraction with 1-alkyl-3-methylimidazolium bis\{(trifluoromethyl)sulfonyl\}a- 
mide ionic liquids: effect of the alkyl-substituent length. J. Phys. Chem. B 111, 4732 (2007).

19 Crosthwaite, J. M., Aki, S.N.V.K., Maginn, E. J. \& Brennecke, J. F. Liquid phase behavior of imidazolium-based ionic liquids with alcohols. J. Phys. Chem. B 108, 5113 (2004).

20 Crosthwaite, J. M., Muldoon, M. J., Aki, S.N.V.K., Maginn, E. J. \& Brennecke, J. F. Liquid phase behavior of ionic liquids with alcohols: experimental studies and modeling. J. Phys. Chem. B 110, 9354 (2006).

21 Chapeaux, A., Simoni, L. D., Ronan, T. S., Stadtherr, M. A. \& Brennecke, J. F. Extraction of alcohols from water with 1-hexyl-3-methylimidazolium bis(trifluoromethylsulfonyl)imide. Green Chem. 10, 1301 (2008).

22 Lachwa, J., Szydlowski, J., Najdanovic-Visak, V., Rebelo, L. P. N., Seddon, K. R., Ponte, M. N., Esperancüa, J.M.S.S. \& Guedes, H. J. R. Evidence for lower critical solution behavior in ionic liquid solutions. J. Am. Chem. Soc. 127, 6542 (2005)

23 Kumelan, J., Kamps, A. P. S., Tuma, D., Yokozeki, A., Shiflett, M. B. \& Maurer, G. Solubility of tetrafluoromethane in the ionic liquid [hmim][Tf $\left.f_{2} \mathrm{~N}\right]$. J. Phys. Chem. B 112,3040 (2008).

24 Aki, S.N.V.K., Mellein, B. R., Saurer, E. M. \& Brennecke, J. F. High-pressure phase behavior of carbon dioxide with imidazolium-based ionic liquids. J. Phys. Chem. B 108, 20355 (2004).

25 Muldoon, M. J., Aki, S.N.V.K., Anderson, J. L., Dixon, J. K. \& Brennecke, J. F. Improving carbon dioxide solubility in ionic liquids. J. Phys. Chem. B 111, 9001 (2007).

26 Arce, A., Earle, M. J., Katdare, S. P., Rodrỳguez, H. \& Seddon, K. R. Mutually immiscible ionic liquids. Chem. Commun. 2006, 2548 (2006).

27 Arce, A., Earle, M. J., Katdare, S. P., Rodrỳguez, H. \& Seddon, K. R. Application of mutually immiscible ionic liquids to the separation of aromatic and aliphatic hydrocarbons by liquid extraction: a preliminary approach. Phys. Chem. Chem. Phys. 10, 2538 (2008).

28 Ueki, T. \& Watanabe, M. Upper critical solution temperature behavior of $\operatorname{poly}(N$ isopropylacrylamide) in an ionic liquid and preparation of thermo-sensitive nonvolatile gels. Chem. Lett. 35, 964 (2006).

29 Ueki, T. \& Watanabe, M. Lower critical solution temperature behavior of linear polymers in ionic liquids and the corresponding volume phase transition of polymer gels. Langmuir 23, 988 (2007).

30 Ueki, T., Karino, T., Kobayashi, Y., Shibayama, M. \& Watanabe, M. Difference in lower critical solution temperature behavior between random copolymers and a homopolymer having solvatophilic and solvatophobic structures in an ionic liquid. J. Phys. Chem. B 111,4750 (2007)

31 Ueki, T. \& Watanabe, M. Macromolecules in ionic liquids: progress, challenges, and opportunities. Macromolecules 41, 3739 (2008).

32 Kodama, K., Nanashima, H., Ueki, T., Kokubo, H. \& Watanabe, M. Lower critical solution temperature phase behavior of linear polymers in imidazolium-based ionic liquids: effects of structural modifications. Langmuir 25, 3820 (2009).

33 Ueki, T., Yamaguchi, A., Ito, N., Kodama, K., Sakamoto, J., Ueno, K., Kokubo, H. \& Watanabe, M. Photoisomerization-induced tunable LCST phase separation of azobenzene-containing polymers in ionic liquid. Langmuir 25, 8845 (2009).

34 Ueki, T., Arai, A. A., Kodama, K., Kaino, S., Takada, N., Morita, T., Nishikawa, K. \& Watanabe, M. A thermodynamic study on the phase transitions of poly(benzyl methacrylate) in ionic liquids as solvent. Pure Appl. Chem. 81, 1829 (2009).

35 Tamura, S., Ueki, T., Ueno, K., Kodama, K. \& Watanabe, M. Thermosensitive selfassembly of diblock copolymers with lower critical micellization temperatures in an ionic liquid. Macromolecules 42, 6239 (2009).

36 Ueki, T., Watanabe, M. \& Lodge, T. P. Doubly thermo-sensitive self-assembly of diblock copolymers in ionic liquids. Macromolecules 42, 1315 (2009).

37 Aoki, S., Koide, A., Imabayashi, S. \& Watanabe, M. Novel thermosensitive polyethers prepared by anionic ring-opening polymerization of glycidyl ether derivatives. Chem. Lett. 11, 1128 (2002).

38 Nakadan, N., Imabayashi, S. \& Watanabe, M. Temerature-induced reversible change in the redox response in phenothiazine-labeled poly(ethoxyethyl glycidyl ether) and its application to the thermal control of the catalytic reaction of glucose oxidase. Langmuir 20, 8786 (2004).

39 Tsuda, R., Kaino, S., Kokubo, H., Imabayashi, S. \& Watanabe, M. Effect of core-shell micelle formation on the redox properties of phenothiazine-labeled poly(ethyl glycidyl ether)-block-poly(ethylene oxide). Colloids Surf. B 56, 255 (2007).

40 Ogura, M., Tokuda, H., Imabayashi, S. \& Watanabe, M. Preparation and solution behavior of thermoresponsive diblock copolymer of poly(ethyl glycidyl ether) and poly(ethylene oxide). Langmuir 23, 9429 (2007).

41 Tsuda, R., Kodama, K., Ueki, T., Kokubo, H., Imabayashi, S. \& Watanabe, M. LCST-type liquid-liquid phase separation behavior of poly(ethylene oxide) derivatives in an ionic liquid. Chem. Commun. 2008, 4939 (2008).

42 Lee, H. N. \& Lodge, T. P. Lower critical solution temperature (LCST) phase behavior of poly(ethylene oxide) in ionic liquids. J. Phys. Chem. Lett. 1, 1962 (2010).

43 Lopes, J.N.A.C. \& Padua, A. A. H. Nanostructural organization in ionic liquids. J. Phys. Chem. B 110, 3330 (2006).

44 Wang, Y. \& Voth, G. A. Tail aggregation and domain diffusion in ionic liquids. J. Phys. Chem. B 110, 18601 (2006).

45 Lopes, J. N. C., Gomes, M. F. C. \& Padua, A. A. H. Nonpolar, polar, and associating solutes in ionic liquids. J. Phys. Chem. B 110, 16816 (2006).

46 Soucup, R. W. \& Sone, K. (Acetylacetonato) $\left(N, N, N^{\prime}, N^{\prime \prime}\right.$-tetramethylethylenediamine)copper(II) tetraphenylborate as a solvent basicity indicator. Bull. Chem. Soc. Jpn. 60, 2286 (1987).

47 Tokuda, H., Tsuzuki, S., Susan, M.A.B.H., Hayamizu, K. \& Watanabe, M. How ionic are room-temperature ionic liquids? An indicator of the physicochemical properties. J. Phys. Chem. B 110, 19593 (2006).

48 Tsuzuki, S., Tokuda, H., Hayamizu, K. \& Watanabe, M. Magnitude and directionality of interaction in ion pairs of ionic liquids: relationship with ionic conductivity. J. Phys. Chem. B 109, 16474 (2005).

49 Romsted, L. S. \& Yao, J. Arenediazonium salts: new probes of the interfacial compositions of association colloids. 4. Estimation of the hydration numbers of aqueous hexaethylene glycol monododecyl ether, C12E6, micelles by chemical trapping. Langmuir 12, 2425 (1996).

50 Quina, F. H. \& Hinze, W. L. Surfactant-mediated cloud point extractions: an environmentally benign alternative separation approach. Ind. Eng. Chem. Res. 38, 4150 (1999).

51 Costa, L. T. \& Ribeiro, M. C. C. Molecular dynamics simulation of polymer electrolytes based on poly(ethylene oxide) and ionic liquids. I. Structural properties. J. Chem. Phys. 124, 184902 (2006).

52 Triolo, A., Russina, O., Keiderling, U. \& Kohlbrecher, J. Morphology of poly(ethylene oxide) dissolved in a room temperature ionic liquid: a small angle neutron scattering study. J. Phys. Chem. B 110, 1513 (2006).

$53 \mathrm{He}$, Y., Li, Z., Simone, P. M. \& Lodge, T. P. Self-assembly of block copolymer micelles in an ionic liquid. J. Am. Chem. Soc. 128, 2745 (2006).

$54 \mathrm{He}, \mathrm{Y}$. \& Lodge, T. P. The micellar shuttle: thermoreversible, intact transfer of block copolymer micelles between an ionic liquid and water. J. Am. Chem. Soc. 128, 12666 (2006).

$55 \mathrm{He}$, Y. \& Lodge, T. P. A thermoreversible ion gel by triblock copolymer self-assembly in an ionic liquid. Chem. Commun. 2007, 2732 (2007).

$56 \mathrm{He}$, Y., Boswell, P. G., Buhlmann, P. \& Lodge, T. P. Ion gels by self-assembly of a triblock copolymer in an ionic liquid. J. Phys. Chem. B 111, 4645 (2007).

$57 \mathrm{He}, \mathrm{Y}$. \& Lodge, T. P. Thermoreversible ion gels with tunable melting temperatures from triblock and pentablock copolymers. Macromolecules 41, 167 (2008).

58 Bai, Z., He, Y. \& Lodge, T. P. Block copolymer micelle shuttles with tunable transfer temperatures between ionic liquids and aqueous solutions. Langmuir 24, 5284 (2008).

59 Sarkar, A., Trivedi, S., Baker, G. A. \& Pandey, S. Multiprobe spectroscopic evidence for 'hyperpolarity' within 1-butyl-3-methylimidazolium hexafluorophosphate mixtures with tetraethylene glycol. J. Phys. Chem. B 112, 14927 (2008).

60 Rodriguez, H., Francisco, M., Rahman, M., Sun, N. \& Rogers, R. D. Biphasic liquid mixtures of ionic liquids and polyehtylene glycols. Phys. Chem. Chem. Phys. 11, 10916 (2009).

Supplementary Information accompanies the paper on Polymer Journal website (http://www.nature.com/pj) 